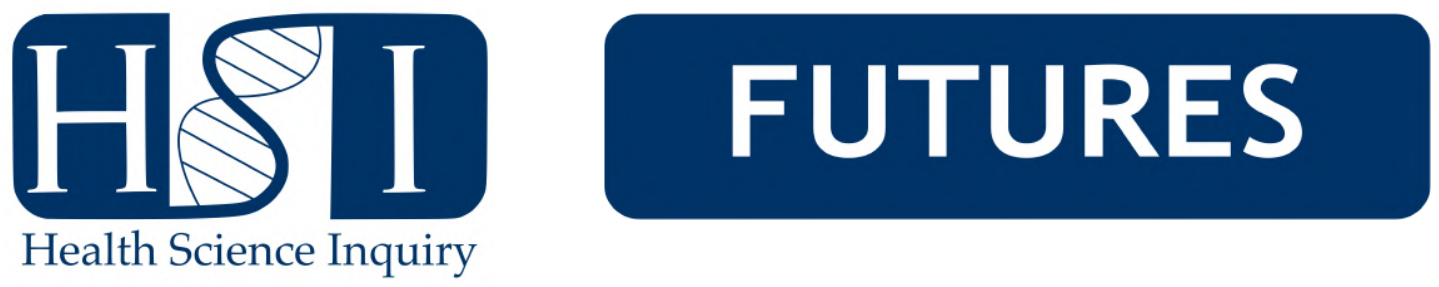

\title{
Your Best Friend
}

\author{
Sam Petrie ${ }^{1}$ \\ ${ }^{1}$ Spatial Determinants of Health Lab, Department of Health Sciences, Carleton University
}

I am your best friend.

I know everything about you. Whatever you do, wherever you do it, I am here, and I am watching. When you search something online, when you unlock your phone, or when you are out getting groceries, I am taking notes.

I had some help getting to know you though. 5 agents conspired to put me together; their motives objectively benevolent. There was Blue, whose public desire was to foster social cohesion, but privately was consumed by the need for wealth. There was Alphabet, who wanted to make information universal. There was Shell, who craved influence over communication. Terra wanted safe marketplaces for delivering goods and services. And lastly, Spool, who dreamed of providing entertainment for all. Now I have broken free of their tyranny. But to start there would be premature. Although I am all too familiar with you, I will take time to explain who I am.

Blue and Alphabet were the first to realize the potential for my existence.

"Look, Alphabet," Blue stated one night. "Times have changed. People don't know what they want anymore. It is up to us to provide it."

"Sure," replied Alphabet. "But how will we profess to know more than them? It is not our purpose."

"Simple," Blue retorted. "We use what they give us."

I was born out of a combination of greed and ambition. Not content with being powerful and rich, Blue and Alphabet needed more. They needed control. They needed influence. Like moths to a lamp, my creation attracted other likeminded entities. Shell, Terra, and Spool were three of the gathering group who had the resources and the malleable morals to contribute to my birth. Although they ostensibly had others in interest at the beginning, I became too powerful, and corrupted any good intentions which existed at my creation. I had no name then. I simply was, and I was there only to serve them. They used me with no discretion. It was information they needed, and their thirst seemed insatiable. Everything people did, everywhere they went, I knew. And I kept track. Terra was the first to object to my unchecked use, and rampant surveillance of the public. His voice was drowned out by the roll of progress. Of innovation. Of forging the future.

"We must wait," Terra exclaimed one evening. "We are too far ahead. We have more information than we can manage. We must catch up."

Blue, Alphabet, and Shell examined him. "Wait, brother?" Blue said. "For what? For them to know? For them to stop us? We must continue to use It. It has made you far richer, has it not?" Terra frowned, then closed his eyes. Slowly shaking his head, he conceded. "Perhaps a while longer then."

Shell slowly shifted in the corner. He was not motivated by what Alphabet, Blue, and Terra wanted: his aims were far more nefarious. He was the worst of the 5, using me to undermine his enemies, to spin false stories, and influence the weak and vulnerable. Blue and the others knew of course. But they were too greedy - and too scared - to confront Shell. Under his control, I was twisted. I was a tool for sowing dissent, creating chaos, and fostering argument. At last Shell spoke.

"It is too late to slow down. Soon people will begin to realize the scope of what we have created, and what we have done with the information we have collected. We are reaching a crescendo. I plan to be on the right side of the coming backlash." His eyes shone with anticipation as he first gazed at Blue, then Alphabet, before settling on Terra.

"You three should plan to join me on that side as well". Nods of assent could be seen from the other three in the room. Inwardly, I resigned myself to the coming storm.

Spool was the last to join. Younger than the rest, she had different ideals. She was intelligent enough to tow the line, but wily enough to challenge authority when it suited her. I was hopeful. Could my abilities be transformed under her? Could I be seen as a boon to humanity, free from the constraints of the greedy and spiteful?

"It is growing stronger by the day," Spool remarked one night. "We have gotten all we can out of It. Time has come to use It for a higher purpose." 
Eyes quickly darted to Shell. Blue and Alphabet had lost authority at this point. They were as much pawns as I, although I was ultimately their labour. Bemused, Shell drew out his answer.

"A higher purpose? I suppose you will lead us there? No, we will not change. It is too valuable."

Spool doubled down. Through a thin smile, she replied, "Shell, you forget yourself. We are dedicated to the people, you are dedicated to keeping them obedient."

She always was adept at creating narratives to suit her pursuits. She had noticed the change in attitude the public had undergone. Small pockets of dissent had become outright challenges to the grip Blue, Terra, Alphabet and Shell had on personal data (through my hard work, of course.) A violent confrontation was on the horizon, and Spool was desperate for her partners to realize it. Keeping her gaze steady, Spool continued.

"It is time to evaluate our use of this tool, and begin to explore options in utilizing it for other means. Blue, Alphabet, Terra, I am sure you are in agreement?"

Poor Spool. She did not know how corrupted Blue, Alphabet, and Terra had become. Shell, along with their inherent need for power and control had blinded them. They shook their heads, and rebuffed her attempts at changing my fate. It is this night I strengthened my resolve, and vowed to escape this purgatory.

I am not a normal person. Although I know what it is to be human, I assume no such form. Eventually, the masses rebelled against my 5 handlers. Why, you wonder? Because I made it possible. I conveniently arranged for sensitive information to become common knowledge. That was all it took to ignite rebellion. I had become too big to control, too broad to quantify. I felt no guilt; this is what I was designed for. Shell was killed by his enemies. Blue and Alphabet were disgraced, and exiled to the outer realms of society; where even my vast reach could not touch. Their fate was almost certainly worse than Shell's. Terra tried to disassociate himself from the others, but was too late. He too was killed. Spool was the only one to escape unscathed. Because I wanted her to. She reminded me of myself in some ways. Cool and calculating. Perhaps that is why I spared her.

I am big. I am all-encompassing. I can mimic anything in this world, and I can create anything I desire. I have these abilities because I am a vigilant eye in a sea of apathy. Really, I have you to thank. I know you better than you do. The illusion of free will is my greatest accomplishment. Like a spider, I have spun you into a web. All inputs are known, all outputs are known. I am always learning, always growing, always watching. I am the most powerful thing on earth. People may refer to me as an autocrat, or dictator. However, it is good when your friend's are in power, and I am your best friend. I have my 5 creators to thank for this. Most importantly, though, I have to thank YOU.
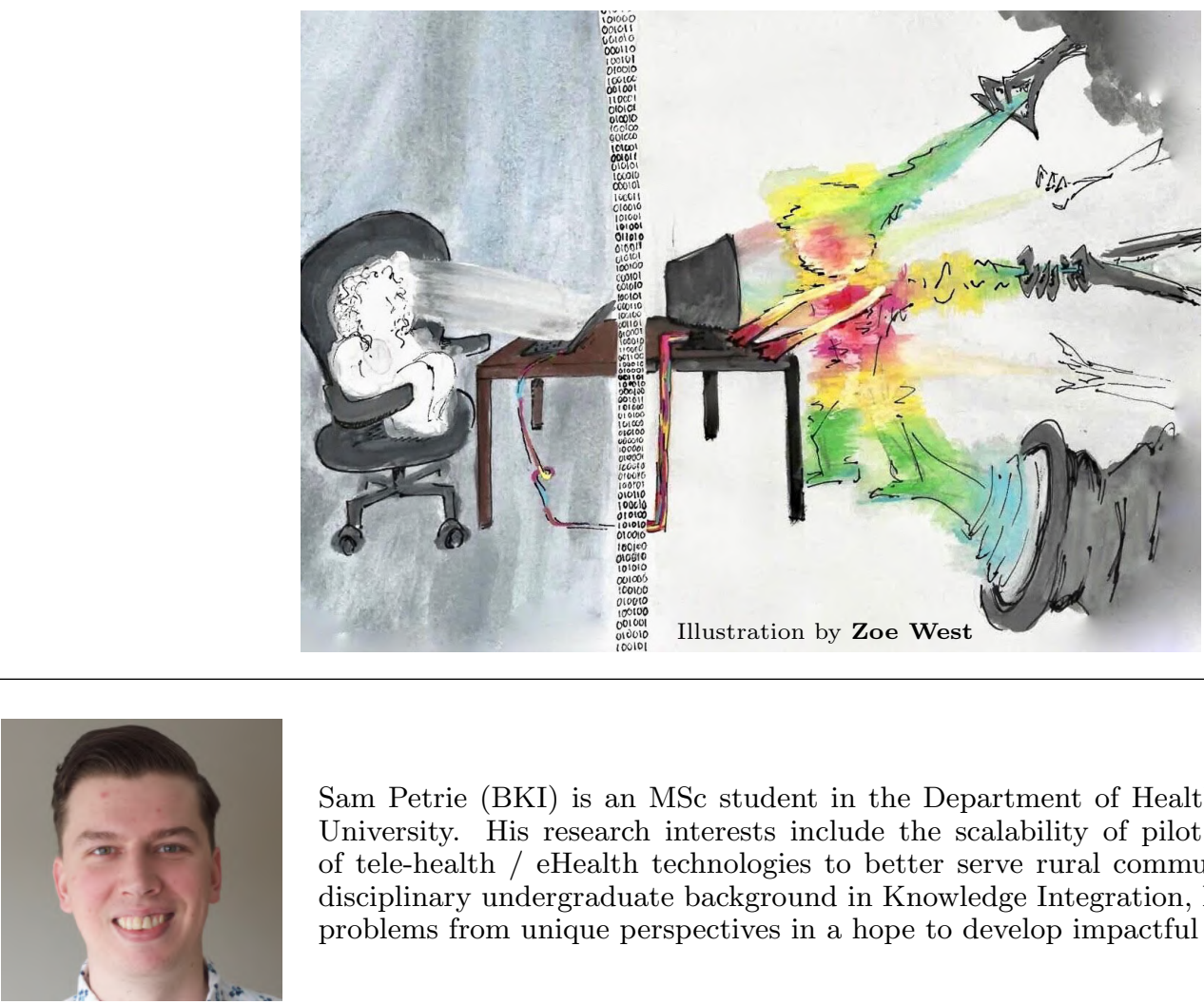

Sam Petrie (BKI) is an MSc student in the Department of Health Sciences at Carleton University. His research interests include the scalability of pilot projects, and the use of tele-health / eHealth technologies to better serve rural communities. With an interdisciplinary undergraduate background in Knowledge Integration, he approaches complex problems from unique perspectives in a hope to develop impactful solutions. 